\title{
Ficções teatrais e cometimentos editoriais
}

\author{
Maria Helena Serôdio
}

No campo da actuação da APCT tem cabido uma importante dimensão internacional, não apenas relativa aos Seminários de Jovens Críticos - que alguns dos nossos associados vêm frequentando e que temos sabido também dinamizar e organizar em Portugal e no estrangeiro -, mas também à participação em congressos e fóruns de mais alargada discussão teórica e analítica.

Foi recentemente o caso do seminário internacional que organizámos em Almada, no passado mês de Julho, no contexto do Festival de Teatro de Almada. Contando com o dinamismo, agilidade e abertura à diversidade que vem caracterizando a organização do festival dirigido por Joaquim Benite, a APCT lançou o tema "Ficções dramatúrgicas e cenográficas: convergências / confrontações" a que responderam alguns dos nossos colegas de outras associações nacionais. Nesse fórum achámos por bem introduzir os nossos convidados a aspectos importantes do teatro em Portugal no que àquele espaço e iniciativa dizia respeito: quer através de uma apresentação - também visual - sobre o que tem sido o Festival de Almada desde a sua primeira realização em 1984, quer através de uma intervenção do arquitecto Manuel Graça Dias sobre a concepção e funcionamento do novo Teatro Municipal de Almada, questões que muito interessaram à plateia internacional ali reunida.

As comunicações, trazidas pelos nossos colegas da Associação Internacional de Críticos de Teatro, preenchem a secção "Dossiê temático" deste número e representam formas de debate interessante, reunindo experiências muito diversas - numa vasta cartografia internacional e intercontinental - e lançando pistas que se podem mobilizar em torno de questões relativas não apenas ao teatro em geral, mas também, muito provavelmente, para pensarmos - e avaliarmos - a realidade artística portuguesa. E aí poderíamos ponderar não apenas alguns dos trajectos criativos de companhias, mas também a escrita dramatúrgica tal como vem sendo praticada - na escrita e em palco - e que, contrariando penúrias anteriores, tem sido recentemente levada à cena com alguma visibilidade, embora, evidentemente, se trate de um esforço a aprofundar e a melhorar. Disso damos conta (ainda que de forma incompleta) quer na secção "Passos em volta" (falando do espectáculo sobre texto de José Maria Vieira Mendes), quer nas "Leituras".
Mas na consideração dessa travessia entre dramaturgia e invenção cenográfica no teatro contemporâneo é importante destacarmos a conferência que Aleks Sierz nos trouxe ao seminário de Almada, contribuindo para mais de perto conhecermos os modos ficcionais que 0 teatro tem recentemente inventado e, também, para perspectivarmos de forma mais apurada essa realidade. Provando que, no cômputo mais geral do que se disse e debateu em Almada, este era um tema candente no panorama artístico de hoje.

Nesta tessitura entre fórmulas dramatúrgicas - de razões mais ou menos "literárias" - e práticas cénicas de modalidades mais físicas, entre o circense e o simbolismo gestual, veja-se o projecto artístico que "Na primeira pessoa" a companhia Circolando nos apresenta através de uma interpelação activa de Paulo Eduardo Carvalho e Isabel Alves Costa.

Provando, todavia, como esta revista procura acompanhar as mais diversificadas pistas de actuação em teatro, reservámos para os "Estudos aplicados" duas importantes contribuições dos filólogos - Burghard Dedner e Luigi Giuliani - que têm trabalhado textos, respectivamente, dos dramaturgos Georg Büchner e Lope de Vega. No trabalho que realizam sobre a matéria textual verificamos não apenas formas de fixação editorial, mas também a inscrição de leituras de documentos da época e mesmo a influência que exercem os processos de publicação a que foram sujeitos em função da própria estrutura do mundo editorial e empresarial do tempo em que escreviam. São, a vários títulos, interessantes formas de pensar as razões culturais que se podem ler e estudar na própria escrita para teatro.

Do que se vai fazendo pelo mundo, fica-nos das "Notícias de fora" a ideia de que, com textos clássicos ou com novas formulações dramatúrgicas, o teatro em Nova lorque ou em Edimburgo serve para interrogar as razões políticas que movem o mundo nos dias de hoje, tal como Donato Loscalzo e Rui Pina Coelho as souberam ler em cena.

Entretanto, se na interneté possivel encontrar hoje assuntos de interesse para conhecermos o teatro, como nos revela Marta Brites Rosa, não deixa de ser apaixonante revisitar o teatro em Portugal no século XVIII e verificar - como tão bem demonstra Maria João Almeida - a 

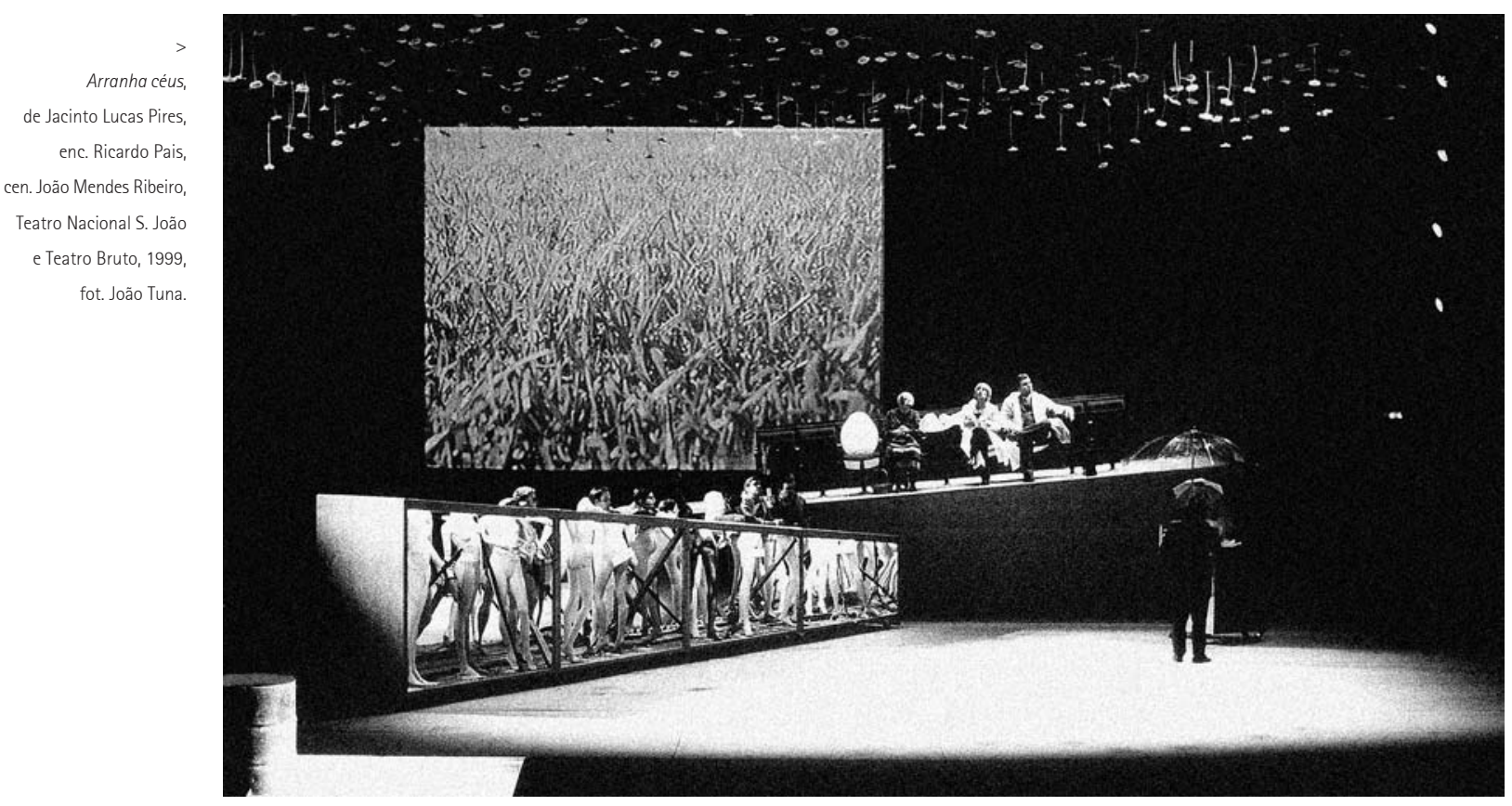

importância que teve na corte portuguesa a presença de um actor como Sacchi e a fortuna que por ele teve Goldoni no teatro em Portugal. Decorrendo de uma investigação aturada no quadro de um doutoramento em Estudos de Teatro pela Faculdade de Letras da Universidade de Lisboa (uma dissertação que a Imprensa Nacional - Casa da Moeda já deu à estampa), a questão de Goldoni não podia deixar de estar presente quando se celebraram os 300 anos do seu nascimento.

Nem sempre, porém as efemérides deixam boas recordações, como verificou Sebastiana Fadda a propósito de uma produção internacional em torno de uma releitura de Goldoni. Mas nessa mesma secção - a dos "Passos em volta" - podemos ler referências a outros espectáculos que merecem aplauso e permitem outro tipo de avaliações críticas, estendendo-se a leitura a produções dos teatros municipais de Lisboa - Maria Matos e São Luiz -, à ZDB Negócio, Casa Conveniente e Ensemble, entre outras.

Merecem ainda destaque neste número outras intervenções criativas, como os livros de que nos falam as "Leituras" - peças (de Jaime Rocha), uma tradução de Rostand (por Vasco Graça Moura), um estudo sobre teatro para crianças (de Glória Bastos) e deambulações em torno de criações teatrais (de Patrícia Portela).

No "Portefólio" reunimos alguma informação relevante sobre o trajecto em teatro de Fiama Hasse Pais Brandão, procurando sinalizar a sua importância como dramaturga e tradutora (entre várias outras instâncias que experimentou na relação com a cena), organizando uma - ainda que singela - forma de memória que recorde o seu inquestionável valor literário e artístico.
Em tempos de inquietação sobre o presente e futuro da cultura e das artes em Portugal - mercê das receitas economicistas e liberais que vêm drasticamente limitando actuações e dissuadindo vontades - prosseguir uma publicação como esta é seguramente um esforço de voluntariosa obstinação por parte de quem aceita assumir esta aventura e de quem partilha connosco o seu saber escrevendo ou traduzindo artigos. Mas no caminho que percorremos temos tido a compreensão de muitos dos que trabalham em teatro e que, para além de criarem por isso a nossa razão de publicar, ainda nos auxiliam, de forma generosa e paciente, com fotografias, documentação e outros materiais imprescindiveis. Entre outros, é justo destacar Gastão Cruz, Cristina Reis, João Tuna, Rodrigo Francisco, Andreia Bento e Nuno Moura. E é ainda justo agradecer formalmente ao Teatro Nacional de S. João e ao Teatro Nacional D. Maria II por aceitarem publicitar na nossa revista.

Prosseguir esta aventura é também uma forma de reconhecermos publicamente que há razões para festejar o teatro e os seus artistas. Por isso lembramos aqui que Luiz Francisco Rebello celebrou em 2007 - com a subida à cena de Desobediência, com encenação de Rui Mendes - 0 60. ${ }^{\circ}$ aniversário da sua presença cénica (datando de 1947, no quadro do Teatro Estúdio do Salitre, a estreia de 0 mundo começou às 5 e 47). Outra razão celebrativa foi o prémio internacional que distinguiu o cenógrafo João Mendes Ribeiro na Quadrienal de Praga, de que nos fala o texto de lan Herbert, e que nos leva aqui a relembrar iconograficamente uma das suas fiç̧ões cenográficas mais inspiradas. 